\title{
A COMUNICAÇÃO ORGANIZACIONAL COMO FERRAMENTA PARA A OTIMIZAÇÃO DO RE- LACIONAMENTO DE UMA BIBLIOTECA COM OS SEUS PÚBLICOS
}

TIAGO ELOY ZAIDAN

Universidade Federal de Pernambuco Recife, Pernambuco, Brasil e-mail: eloyzaidan@gmail.com 
A COMUNICAÇÃO ORGANIZACIONAL COMO FERRAMENTA PARA A OTIMIZAÇÃO DO RELACIONAMENTO DE UMA BIBLIOTECA COM OS SEUS PÚBLICOS

Resumo: O presente artigo tem como foco as bibliotecas abertas gratuitamente ao público e com acervo circulante, e visa estudar a comunicação organizacional enquanto ferramenta que torne possível a amplificação do número de usuários dessas bibliotecas, bem como o estreitamento da relação entre o espaço cultural e os seus diversos públicos. Palavras-chave: Comunicação organizacional; Biblioteca; Relações com a comunidade; Comunicação dirigida aproximativa.

\section{LA COMUNICACIÓN ORGANIZACIONAL COMO HERRAMIENTA PARA OPTIMIZAR LA RELACIÓN DE UNA BIBLIOTECA CON SU PÚBLICO}

Resumen: Este artículo se centra en las bibliotecas libres abiertas al pública y con una colección disponible para préstamo y tiene como objetivo estudiar la comunicación organizacional como una herramienta que permite la amplificación del número de usuarios de estas bibliotecas, así como el fortalecimiento de la relación entre el espacio cultural y sus diversas audiencias. Palabras clave: Comunicación Organizacional; Biblioteca; Relaciones con la comunidad; comunicación dirigida aproximada.

ORGANIZATIONAL COMMUNICATION AS A TOOL FOR RELATIONSHIP OPTIMIZATION OF A LIBRARY WITH ITS PUBLIC

Abstract: This article focuses on the libraries open to the public and with books loan. Objective study organizational communication as a tool to increase the number of users of these libraries. Also aims to improve the relationship between the library and its stakeholders. It is intended to also indicate the basic stakeholders of a library and present guidelines for the relationship with these. Keywords: Organizational communication; Library; Community relations; Directed communication approximate. 


\section{INTRODUÇÃO}

Este artigo se trata de um relato de pesquisa em estágio inicial e está calcado em dois recortes:

a. As bibliotecas, de natureza pública ou privada, abertas gratuitamente ao público, mediante um simples cadastro, com o qual se dá acesso ao empréstimo dos livros.

b. A comunicação organizacional enquanto ferramenta que torne possível a amplificação do número de usuários dessas bibliotecas, bem como o estreitamento da relação entre o espaço cultural e os seus diversos públicos.

A quantidade de bibliotecas no Brasil não é suficiente para suprir a demanda de um país continental. Os espaços existentes dependem, em grande parte, do Estado, em suas diversas esferas - principalmente dos municípios, uma vez que as bibliotecas públicas estaduais se concentram nas capitais (BORGES, 2010). Curiosamente, a pesquisa Retratos da Leitura no Brasil, do Instituto Pró-livro, encetada com 5 mil pessoas em 315 municípios, entre junho e julho de 2011, revelou que, dentre aqueles que reduziram os seus volumes de leitura, apenas $4 \%$ atribuíram a retração à dificuldade de acesso aos livros, o que abrange não apenas a falta de bibliotecas nas proximidades da residência, como, ainda, a ausência de livrarias ou o alto preço dos livros. Já $78 \%$ daqueles dentre os quais passaram a ler menos, admitiram que o motivo foi o desinteresse, o que abrange a alegação de falta de tempo, falta de paciência para ler, ou, ainda, a preferência por outras atividades (CIEGLINSKI, 2012).

O estudo citado quebra paradigmas ao apontar que as políticas para a formação de leitores não devem passar apenas pela disponibilização de espaços como muitos dos que existem hoje, incapazes de seduzir potenciais leitores. Tão importante, ou mais, que a acessibilidade aos livros, deve ser os esforços para se gerar interesse, para se conquistar a atenção e a preferência das pessoas, as quais possuem uma miríade de outras opções.

A utilização das estratégias estudadas e sugeridas neste trabalho tem o potencial de somar forças em torno de um dos objetivos precípuos de qualquer biblioteca: contribuir para a formação de leitores. Isso, no entanto, só será possível se o espaço for efetivamente visitado. Sem audiência, não há como influenciar as pessoas, as quais, antes, precisam ter acesso ao conteúdo. 
A COMUNICAÇÃO ORGANIZACIONAL COMO FERRAMENTA PARA A OTIMIZAÇÃO DO RELACIONAMENTO DE UMA BIBLIOTECA COM OS SEUS PÚBLICOS

O que se observa empiricamente, no entanto, é um paradoxo: enquanto as bibliotecas abertas ao público geral e de forma gratuita estão relativamente vazias, as livrarias, as quais cobram pelos livros do acervo, estão cheias de leitores. A comunicação organizacional pode ajudar a reverter este quadro, posicionando os espaços culturais como áreas para a prática do lazer cultural, para a consulta descompromissada ao acervo, para o passeio mais demorado, e não apenas para a pesquisa objetiva, ou para a retirada de um título pré-selecionado. E, nesse sentido, mesmo estratégias do varejo na estruturação do ambiente podem contribuir para que as bibliotecas sejam atualizadas e ressignificadas.

O objetivo central deste paper - concentrado metodologicamente na pesquisa exploratória - é, portanto, o de estudar estratégias de comunicação organizacional voltadas para bibliotecas - de caráter público ou privado e de acesso gratuito - como contributos para ampliar a base de visitantes e usuários ativos destas. Por questão de espaço, este artigo não se propõe a tratar das ferramentas online, uma vez que as diversas possibilidades de comunicação organizacional via internet demandariam mais páginas. Pelo mesmo motivo, falta de espaço, neste artigo, não nos detivemos, tanto quanto o merecido, no relacionamento com os jornalistas, no contexto da comunicação organizacional da biblioteca. Dito isto, propomo-nos a discutir tais pontos em outros dois paper específicos.

\section{DESENVOLVIMENTO}

\subsection{Os públicos e as linhas gerais de relacionamento}

A biblioteca1, como de resto qualquer organização, deve pavimentar uma interação planejada com uma miríade de públicos os quais são, em alguma medida, partes interessadas ou passíveis de sofrer alguma influência advinda da iniciativa do espaço cultural.

\footnotetext{
1 Uma biblioteca pode ser definida a partir de sua condição, de propiciadora da “(...) existência de alguma forma de organização que permita encontrar o que se deseja (...)" (MILANESI, 2002, p. 12). Também representa o esforço para se proteger um patrimônio humano, calcado no conhecimento acumulado pelas gerações anteriores e sobre o qual, novos conhecimentos e avanços podem ser construídos.
} 
Abaixo, sugerimos uma lista básica de stakeholders ${ }^{1}$ de uma biblioteca. Não se trata de uma lista exaustiva, apenas ilustrativa, livremente baseada em Fortes (2003). Embora tenhamos proposto uma estruturação sistematizada, com a finalidade de facilitar a compreensão, os segmentos apresentados a seguir podem possuir pontos de contatos diversos e se sobreporem, na proporção em que “(...) um mesmo cidadão pode estar perante diversas controvérsias, pertencendo a uma ou a outra tipologia de público" (FORTES, 2003, p. 81).

a. Funcionários fixos: os bibliotecários.

b. Estagiários: especialmente na área de ciência da informação, os quais podem vir a ser incorporados aos quadros da biblioteca após a conclusão do curso.

c. Funcionários terceirizados: auxiliar de limpeza, segurança e jardineiro (mão de obra eventual). Embora não seja diretamente vinculado à biblioteca, e sim à empresa terceirizada fornecedora, o terceirizado deve receber treinamento contínuo, especialmente no sentido de imergir nas políticas, missão, valores e cultura do espaço cultural. “(...) O terceirizado 'fala' em nome da organização e as pessoas não conseguem distingui-lo dos funcionários fixos. Qualquer informação incorreta ou falta de atenção será consignada como falha da empresa, o que pode comprometer o seu conceito público" (FORTES, 2003, p. 74).

d. Familiares e dependentes dos funcionários. O objetivo é que esta parcela dos stakeholders, enquanto parte da comunidade, seja usuária do espaço cultural e se beneficie do serviço ofertado e do trabalho de seus parentes, o que certamente motivará os funcionários.

e. Conselhos de classe e sindicatos: dos profissionais de ciências da informação.

f. Fornecedores de serviços: empresa fornecedora do serviço de hospedagem do website da biblioteca; empresa terceirizada fornecedora de recursos humanos, como auxiliar de limpeza e segurança e, por fim, concessionários de serviços públicos - companhias de água, de luz, de telefonia e de internet.

g. Fornecedores regulares de bens: livreiros, inclusive os de alfarrábios, enquanto fornecedores de títulos para o acervo da biblioteca. A conquista

1 Stakeholders “(...) são indivíduos e/ou organizações que estão ativamente interessados em um projeto ou cujos interesses podem ser positiva ou negativamente afetados pela execução ou conclusão deste projeto" (DAYCHOUW, 2007, p. 21). 
A COMUNICAÇÃO ORGANIZACIONAL COMO FERRAMENTA PARA A OTIMIZAÇÃO DO RELACIONAMENTO DE UMA BIBLIOTECA COM OS SEUS PÚBLICOS

da boa vontade por parte dos fornecedores pode favorecer os negócios. 0 relacionamento pode contemplar informações aos livreiros de alfarrábios sobre os segmentos editoriais de maior interesse da biblioteca e ao estado das obras aptas a serem fornecidas, o que agilizaria e otimizaria a relação comercial.

h. Escolas e universidades: através das quais a biblioteca pode iniciar um relacionamento com potenciais recursos humanos, facilitando o recrutamento (no caso das universidades) e, por meio das quais alcançará, potencialmente, uma parcela significativa dos targets do espaço cultural, os estudantes. No caso das universidades, o relacionamento resulta ainda em parcerias no campo da extensão universitária e na possibilidade de consulta a especialistas.

i. Investidores: categoria de público delicada, por envolver parceiros importantes para a viabilização do negócio. Envolvem aqueles com os quais se articulam “(...) permutas de qualquer espécie (...)” (FORTES, 2003, p. 75). Aqui estão contidos, portanto, os bancos, estabelecimentos de crédito e os doadores - no caso da biblioteca, mais comumente, os doadores de livros. Universidades, por meios de projetos de extensão, podem vir a se tornar investidoras, podendo prover recursos tecnológicos, mão de obra e até mesmo instalações para oportunizar a iniciativa. A transparência e a informação constante devem ser a tônica da relação.

j. Usuários cadastrados: público consumidor a respeito do qual a biblioteca reunirá mais informações e que estará apto a solicitar empréstimos de livros. O objetivo precípuo da relação é fazer com que os usuários aumentem a frequência e o tempo de duração das visitas à biblioteca, bem como, ampliem a solicitação de empréstimos de livros.

k. Público visitante: frequentadores esporádicos, eventuais ou constantes que, por algum motivo, não efetuaram cadastro na biblioteca. O objetivo precípuo da relação é fazer com que os públicos visitantes tornem-se usuários cadastrados.

I. Comunidade: é de se esperar que os membros da comunidade sejam usuários ativos do espaço. Beneficiando-se da biblioteca, a vizinhança assumirá, mais facilmente, uma atitude de cooperação e de boa vontade com relação à iniciativa. Por este motivo, estratégias específicas devem ser encetadas para facilitar a integração da vizinhança à biblioteca. Enquanto um dos consumidores prioritários, a comunidade pode trazer novos usuários para o espaço, a partir do boca a boca - amigos, parentes, colegas do trabalho - 
contribuindo assim com a ampliação da base de cadastrados. Estão inclusos no segmento comunidade, formadores de opinião importantes, como lideranças comunitárias e líderes religiosos.

m. Grupos organizados: tais como aqueles de defesa dos direitos humanos, de ambientalistas, de defesa dos direitos dos animais, de movimentos de defesa do consumidor, dentre outros. Com estes, “(...) as relações serão estabelecidas pela transparência das ações da companhia e pelo acatamento de sugestões, considerando-se que são entidades especializadas e preocupadas com assuntos e temas específicos (...)" (FORTES, 2003, p.212). Tais entidades devem ser convidadas a contribuir com sugestões de títulos para a biblioteca, a partir do know how de cada uma. Em alguns casos, as entidades podem até mesmo doar cópias de suas próprias publicações, para figurarem no acervo do espaço cultural a amplificar a divulgação das mensagens de suas causas. Esta ação não apenas é consonante com uma política de relações públicas, ao mostrar o quanto a biblioteca se importa com as causas oriundas de demandas da sociedade civil, como, ainda, serve de fonte para a constituição de um acervo plural, que contempla as diversas demandas e segmentos sociais.

n. Celebridades: segmento elencado por Fortes (2003, p.79) como receptores de mensagens institucionais. Além de influenciarem os demais, geram - em suas interações com a biblioteca - possibilidades de sugestões de pauta à imprensa. As celebridades serão atraídas para a causa, enquanto figuras públicas que são, tanto quanto a biblioteca “(...) mostrar-se atualizada, correta e que a associação à sua marca pode trazer benefícios" (FORTES, 2003, p. 212). Da mesma forma que a celebridade pode se beneficiar da associação com a causa, a causa pode se beneficiar da associação com a celebridade, a qual se torna uma espécie de porta-voz da entidade. No entanto, no caso de um escândalo ou notícia negativa envolvendo a personalidade, a causa pode sair prejudicada (MARCONI, 2009, p. 139).

o. Jornalistas e meios de comunicação: formadores de opinião e, de certa forma, representantes da sociedade, motivo pelo qual devem ser atendidos, em suas solicitações, com presteza e honestidade. Mas não só. Sugere-se uma postura proativa, por meio do envio regular de sugestões de pauta relevantes e consonantes com as particularidades de cada veículo.

p. Governo: dos diversos poderes - principalmente do Executivo e do Legislativo - e nas diversas esferas, sobretudo através de seus órgãos de cultura, especialmente aquelas gestoras ou mediadoras de fundos de incen- 
A COMUNICAÇÃO ORGANIZACIONAL COMO FERRAMENTA PARA A OTIMIZAÇÃO DO RELACIONAMENTO DE UMA BIBLIOTECA COM OS SEUS PÚBLICOS

tivo. O relacionamento com o poder público tem a faculdade de gerar boa vontade deste com a iniciativa da biblioteca. O relacionamento com as autoridades deve ocorrer no campo institucional e não personalista, de modo a evitar vinculação da instituição ao político e, consequentemente, ressentimentos perante aqueles que podem vir a assumir o poder em um futuro próximo.

q. Outras bibliotecas e espaços de lazer cultural e entidades representativas dos setores em que estão insertas a organização: como associações de bibliotecas ou comitês de incentivo à leitura etc. O relacionamento pode propiciar a troca de experiências e informações úteis.

Existe ainda o público em potencial. Os integrantes deste representam um desafio na medida em que: "encontram-se adiante do público externo, a empresa não os conhece, e seus 'componentes' mantêm um tipo de indiferença ou desconhecimento relativo à empresa” (FORTES, 2003, p. 81). Além de curiosos e pessoas isoladas, outros membros do público em potencial podem ser elencados a partir de uma observação acurada do ao redor. Candidatos a vestibulares e concursos públicos; frequentadores de algum curso; religiosos domiciliados em mosteiros, seminários, conventos; jovens ou adultos hospedados ou frequentadores em/de instituições sociais, beneficentes etc. Todos estes podem vir a se tornar um público de fato da biblioteca.

\subsection{O público interno}

Por público interno se entende, basicamente, os funcionários de uma organização - mesmo os que não estejam fisicamente próximos da instituição, como aqueles que trabalham em home-office, por exemplo - e os familiares e dependentes destes (ANDRADE, 2003, p.95).

A comunicação interna é uma das ferramentas estratégicas basilares na pavimentação do relacionamento com o público interno. Trata-se de

\footnotetext{
(...) um setor planejado, com objetivos bem definidos, para viabilizar toda a interação possível entre a organização e seus empregados, usando ferramentas da comunicação institucional e até da comunicação mercadológica (para o caso do endomarketing ou marketing interno) (KUNSCH, 2002, p.154).
}

Não se pode confundir comunicação interna com transmissão de informações. Não basta apenas munir os colaboradores de informações. É pre- 
ciso cultivar o diálogo, a interação, o que é inerente a verdadeira comunicação. As reivindicações precisam ser apreciadas e respondidas, mesmo que não possam ser atendidas (MARCONI, 2009, p.125). Caso contrário, os canais de interação colaborador-organização perdem a credibilidade e os colaboradores sentirão que suas opiniões não possuem valor.

Também não basta disponibilizar canais de informação, por mais variados que estes sejam, se as mensagens enviadas não são processadas ou aceitas pelos destinatários. Por isso a importância de, na comunicação, se respeitar as diferenças entre os distintos colaboradores. Não se pode negar que, “(...) pela própria natureza dos cargos dentro de uma organização (...), as pessoas tenham diferentes níveis de escolaridade e formação e, assim, não recebam ou apreciem determinadas questões corporativas do mesmo modo que outras o fazem" (MARCONI, 2009, p.116). A mensagem que falará ao bibliotecário, possivelmente não funcione para o auxiliar de limpeza. Ambos, no entanto, são importantes para a existência da biblioteca, e, por isso, precisam ser alvos da comunicação interna. Discriminação é não estar atento a eventuais lacunas que ocorram na comunicação perante determinados segmentos de públicos internos.

A criatividade, somada à diversidade de mídias existentes, são contributos para se alcançar os diferentes receptores de forma eficiente. Para discorrer sobre assuntos demasiadamente técnicos, por exemplo, a organização pode valer-se de uma revista em quadrinhos. A título de ilustração, esta mídia pode ser empregada com os auxiliares de limpeza, os quais estarão em contato direto com o acervo, para introduzi-los sobre aspectos relacionados à conservação dos livros. A revista poderia responder, dentre outras questões, quais os produtos e materiais podem ser usados ou não na limpeza das estantes e do salão onde estão dispostos os livros da biblioteca.

A fórmula, evidentemente, não é matemática. Não são todos os casos em que a mídia revista em quadrinhos cabe de forma eficiente. Todavia, o importante é ter em mente que “(...) para se comunicar com funcionários de modo a promover respeito, lealdade e melhor relacionamento, uma comunicação não precisa ter o aspecto de uma circular oficial do governo federal" (MARCONI, 2009, p.123).

O contato pessoal com o gestor tende a ser o preferido pelos colaboradores (MARCONI, 2009, p.125), e, por isso, deve sempre ser considerado. Nesta linha, grupos de discussão, para se colher opiniões e sugestões dos colaboradores, podem ser empregados. Nas reuniões, por seu turno, o for- 
A COMUNICAÇÃO ORGANIZACIONAL COMO FERRAMENTA PARA A OTIMIZAÇÃO DO RELACIONAMENTO DE UMA BIBLIOTECA COM OS SEUS PÚBLICOS

mato "assembleia" pode ser substituído por outro, no qual, diretoria e colaboradores estejam no mesmo nível, lado a lado, “(...) e não um de frente para o outro como se fossem debater em lados opostos" (MARCONI, 2009, p.127).

\subsection{Diretrizes da comunicação}

Por mais que o público-alvo de uma organização seja amplo e genérico (amplitude é um dos atributos que se espera da audiência de uma biblioteca), tentar contemplar e influenciar a todos os segmentos com uma mesma mensagem não é recomendado, especialmente se há busca pela eficiência. Até porque, "a utilização de estratégias de marketing de amplo alcance, com grande cobertura, visando a atingir a grande massa, pode perder algumas oportunidades importantes para melhorar a imagem e a reputação da empresa dentro de determinados alvos (targets)" (MARCONI, 2009, p.31).

É pertinente ter alguma noção e levar em consideração o grau de entendimento e a bagagem educacional e cultural de cada um dos receptores, dos diferentes públicos da biblioteca, com vistas a adequar todo e qualquer material de comunicação organizacional de modo a torná-los mais eficientes. Conhecer os grupos de receptores é, portanto, necessário. O que não muda entre todos os stakeholders é a necessidade destes merecerem respeito por parte da biblioteca, razão precípua, inclusive, da adequação dos discursos da comunicação organizacional.

A compra de espaços pelos meios de comunicação de massa costuma ser vista como um caminho atalhado para fazer uma marca ou produto ser percebido por uma grande quantidade de pessoas em um curto espaço de tempo. Contudo, os espaços de propaganda disponibilizados pelos mass media não estão imunes a saturação, motivo pelo qual o anunciante não pode prescindir das reprises, sob pena da mensagem não se destacar em meio ao ruído composto por inúmeros outros apelos propagandísticos. A necessidade da redundância na exibição das mensagens soma-se aos altos custos inerentes à abordagem pelos meios de comunicação de massa, o que certamente inviabiliza tal estratégia de marketing pelas bibliotecas.

Uma das alternativas para as bibliotecas é a priorização de uma comunicação dirigida, destinada aos diferentes segmentos de públicos os quais compõem o alvo da instituição. Por atingir bem menos pessoas, a conta total da comunicação segmentada tende a ser mais barata. À questão do cus- 
to, soma-se a eficiência. Há menos riscos de se desperdiçar o envio de uma mensagem para um segmento do público diverso daquele que se pretendia alcançar. E, mesmo que a intenção fosse a de espalhar uma determinada mensagem generalística para a maior quantidade de pessoas possível, os custosos meios de comunicação de massa poderiam não ser suficientes, uma vez que "o público, antes mensurado como massa, agora está espalhado pelas diversas mídias alternativas" (MARCONI, 2009, P.44).

Outra estratégia a qual não pode ser desprezada, inserindo-se, por isso, como diretriz, é a da conquista de mídias espontâneas, não oneradas, através, por exemplo, da assessoria de imprensa.

\subsection{Imagem e reputação}

As escolhas dos consumidores de bens e usuários de serviços são influenciadas em grande parte pela imagem que estes têm das organizações e pela reputação destas.

A imagem é a percepção que o público tem, em sua mente, da organização. Nem sempre é de fácil compreensão, por estar no campo do imaginário das pessoas e, por conseguinte, ser abstrata, subjetiva. No entanto, se baseia naquilo que a organização “(...) pode ter depreendido de discussões, comentários propaganda, mala direta (...), elogio (ou crítica) feita boca a boca ou praticamente qualquer outra fonte" (MARCONI, 2009, p.71). Pode-se dizer que a imagem gestada tem a ver com a relação dos públicos com os inputs emitidos pela organização. Entenda-se por inputs “(...) uma grande variedade de manifestações das organizações, por meio dos seus atos e da comunicação" (KUNSCH, 2002, p. 171). No caso da biblioteca, os inputs serão constituídos por elementos que vão do atendimento pelo bibliotecário no balcão de empréstimos de livros até todo o material promocional ou institucional do espaço.

Já a reputação, por seu turno, “(...) é testada com o tempo, normalmente sugerindo história, consistência e certo nível de previsibilidade no desempenho ou comportamento" (MARCONI, 2009, p. 72). A reputação é um patrimônio intangível de qualquer organização e, como tal, deve-se zelar por ela. A reputação, construída no relacionamento com um indivíduo, integra as percepções deste a respeito de uma organização. Depois de constituída, tal percepção até pode ser alterada, mas não sem tempo e dinheiro (MARCONI, 2009, p. 73). 
A COMUNICAÇÃO ORGANIZACIONAL COMO FERRAMENTA PARA A OTIMIZAÇÃO DO RELACIONAMENTO DE UMA BIBLIOTECA COM OS SEUS PÚBLICOS

Uma rede de varejo que anuncia uma mercadoria, mas que, recorrentemente, não disponibiliza o produto anunciado aos consumidores, sofrerá um abalo em sua reputação. O mesmo pode-se dizer de uma biblioteca, a qual anuncia determinados títulos em seu acervo, sem de fato possuí-los. A frustração do usuário que não encontrou o título prometido certamente somar-se-á aos elementos constituintes da percepção com relação ao espaço cultural. Neste caso, a biblioteca não foi previsível em seu desempenho. Reside aqui, também, a relevância de se manter o acervo atualizado e qualificado. Se, de forma rotineira, o usuário não encontrar nas prateleiras aquele título de que precisa ou deseja, tenderá a descartar a biblioteca por deficiência de reputação.

Da mesma forma o desrespeito ao horário de funcionamento divulgado pode frustrar o usuário e abalar a reputação do empreendimento. Por outro lado, se a biblioteca respeita o horário de funcionamento divulgado, mantendo-se plenamente disponível nos horários indicados, estará fornecendo um nível de previsibilidade que influenciará a reputação do espaço. Isto cabe ainda para a qualidade do acervo, do atendimento, da estrutura física etc. Entre duas opções de lazer cultural, o usuário terá mais em conta aquela em que, com base em experiências anteriores, atendeu as suas demandas de forma mais consistente. Não por acaso, algumas organizações adotam estratégias, permeado suas rotinas produtivas, com vistas a padronizar os procedimentos. A manutenção de um elevado nível de previsibilidade na prestação do serviço, buscando a consonância com a expectativa prévia do usuário, é certamente um dos motivos de tais normatizações.

\subsection{Publicações e folheteria}

Canais escritos, impressos ou digitalizados, integram o arsenal dos instrumentos à disposição da comunicação organizacional, sem exigir, necessariamente, grande monta de recursos - especialmente nos formatos digitais. Os materiais escritos são relevantes na medida em que “(...) asseguram uma durabilidade maior das informações veiculadas e servem como material de referência para diversos grupos, embora o seu uso indistinto acarrete perda de relevância" (FORTES, 2003, p. 255). Conforme é possível depreender da citação de Fortes, o potencial de segmentação oferecido pela comunicação escrita não deve ser desprezado.

A comunicação organizacional do espaço cultural pode contemplar a 
confecção de um house organ² periódico, cujo público-alvo sugerido é o externo, precipuamente os usuários cadastrados na biblioteca, que poderão atuar como multiplicadores informais do espaço, repassando, inclusive, o impresso informativo do centro cultural para amigos, parentes e vizinhos, dentre outros. Vale lembrar que, como o público-alvo está cadastrado na biblioteca, supõe-se que este possui alguma intimidade com a leitura.

A distribuição do house organ pode ser feita mediante pontos de disponibilização. O principal deles será a própria biblioteca (pois, como foi dito, o público estratégico é aquele cadastrado e composto por usuários da instituição). Por via reflexa, espera-se atingir os parentes, vizinhos e amigos dos frequentadores. Como alternativa secundária, mas não menos pertinente, para a obtenção do boletim, figura os balcões dos pontos de comércio da comunidade. Padarias, oficinas, papelarias, mercados etc. A mala-direta, pelos custos envolvidos, não se configura como opção viável.

Os serviços gráficos implicarão custos significativos, o que pode inviabilizar completamente o projeto do impresso informativo. Algumas alternativas, todavia, podem ser ponderadas. Em lugar de ser impresso, o informativo pode ser disponibilizado em PDF, por email e no website do centro cultural.

Outra possibilidade é o encarte ${ }^{3}$. Quanto aplicado, inserto em veículos de comunicação de massa, representa um alto custo, o que o torna inviável para a realidade orçamentária dos espaços culturais - a menos que haja uma parceria com o jornal ou revista. Sugerimos uma adaptação deste canal para o seu uso no interior dos livros e periódicos do acervo da biblioteca.

Os encartes devem trazer pequenas sinopses de outros títulos do acervo, acompanhados da imagem da capa do livro, como forma de sugestão. Trata-se de um canal que possibilita uma comunicação dirigida na medida em que os livros sugeridos em cada encarte podem ser de temática consonante com o assunto do livro onde o impresso está encartado. Este canal

2 Embora o termo house organ seja hoje utilizado indistintamente para nominar os jornais e revistas corporativos voltados para os públicos interno ou externo, um significado convencionado em 1958, pela Conferência dos Presidentes das Entidades Filiadas à Federação das Associações Européias de Redatores de Jornais de Empresa (FEIEA) destinou o termo house organ para as publicações reservadas ao público externo. O jornal interno foi denominado de house-journal (REGO,1984, p.33).

3 Trata-se de anúncio "(...) grampeado ou colado em revistas ou solto nos jornais, que não conserva a numeração do periódico de massa” (FORTES, 2003, p. 257). 
A COMUNICAÇÃO ORGANIZACIONAL COMO FERRAMENTA PARA A OTIMIZAÇÃO DO RELACIONAMENTO DE UMA BIBLIOTECA COM OS SEUS PÚBLICOS

funcionaria, assim, como uma espécie de trailer, convidando, de antemão, os leitores de uma determinada obra a lerem, também, outros

títulos que poderiam interessá-lo, dada a semelhança temática entre as obras. Eventualmente, obras de temáticas não totalmente similares podem ser sugeridas como forma de convidar o leitor a explorar outros gêneros. 0 bom senso, no entanto, deve prevalecer.

Com base em Fortes (2003), outras opções de veículos impressos podem ser consideradas como instrumentos de comunicação organizacional destinados ao público geral. Os usos de tais alternativas, no entanto, por onerarem a biblioteca, devem se ponderados.

a. Volante ${ }^{4}$ : versátil, de fácil manuseio e repasse, pode ser utilizado pela biblioteca para divulgar a programação mensal das exposições no hall ou dos eventos previstos para o auditório. Pode incluir ainda uma pequena sinopse de um título escolhido como o livro do mês. O volante é propício ainda para a divulgação do regulamento da biblioteca, destinado, sobretudo, aos usuários recém-cadastrados.

b. Cartão postal: a depender da cidade onde está instalada, ou de seu porte, a biblioteca pode tornar-se um ponto turístico. Especialmente nestes casos, o espaço cultural tem a faculdade de disponibilizar aos visitantes, um cartão postal com a foto da biblioteca, reservando-se o anverso para a legenda da imagem e para o manuscrito do remetente (FORTES, 2003, p. 260). O envio de correspondência é cada vez mais escasso, de modo que o cartão postal pode funcionar como um souvenir para o próprio visitante guardar de lembrança. Embora possa ser utilizado como instrumento de comunicação organizacional, também pode ser cabível a sua venda, como forma de incrementar a renda do espaço.

c. Livro ou opúsculo: instrumento mais caro, o qual, recomenda-se, seja reservado a formadores de opinião - como a membros da imprensa -, e gestores públicos. Pode ser ainda remetido a outras bibliotecas. Um livro transmitiria informações relativas ao empreendimento, ao passo em que, na mesma proporção, contribuiria com a preservação da memória da organização. Seu conteúdo contemplaria, além de dados recentes, a história da biblioteca, a biografia de seus idealizadores e relatos de atuais e ex-colaboradores. O ideal é que a obra - não raro reservada a ocasiões especiais - seja

4 Impresso simples, em folha solta, em uma face ou dobrado ao meio (FORTES, 2003, p.259). É muito utilizado para divulgar atividades culturais, como a programação semanal do cinema. 
ricamente ilustrada, com fotos e reproduções de documentos e artigos de divulgação antigos (FORTES, 2003, p. 261-262; 267). O custo elevado pode levar a gestão da biblioteca a optar pela publicação de tais informações e imagens em hotsite específico inserto no website institucional.

d. Jornal mural ${ }^{5}$ ou mural ${ }^{6}$ : Pelo fato de exigirem que o leitor mantenha-se em pé, em locais de circulação de pessoas, não se pode esperar que o jornal mural ou o mural possuam o mesmo índice de leitura de um house organ. Nem que possuam, quantitativamente, o mesmo conteúdo - até porque o tamanho das letras precisam ser maiores.

e. Revista em quadrinhos: segundo Fortes, "nas empresas é comum a criação de personagens que, por intermédio de desenhos e legendas, criam histórias que ajudam a informar e instruir crianças e jovens sobre determinados assuntos com certo grau de complexidade (...)" (FORTES, 2003, p. 270-271). No caso da biblioteca, os custos implicados na confecção deste material inviabilizam o seu uso em larga escala. Ainda assim, as revistas em quadrinhos podem ser utilizadas como instrumento de comunicação com o público interno, transmitindo informações de ordem técnica de forma mais leve e adequada a receptores específicos.

f. Manual de consulta para o público interno: Fortes (2003, p. 271-272) distingue o manual de identidade visual e o manual de organização. O primeiro tem como foco a utilização da marca da organização, com vistas a uma padronização a qual possibilite a formatação de uma identidade visual sólida; o segundo, por meio de opúsculos, versa sobre as “(...) diretrizes, os preceitos, formulários, padrões, procedimentos e as rotinas de uma instituição" (FORTES, 2003, p.273). Sugerimos a fusão de ambas as publicações em um só manual, destinado ao público interno. A publicação pode ser distribuída para cada um dos colaboradores, ou, impressa em poucas unidades, disponibilizada para consulta - e empréstimo - em local reservado aos funcionários da biblioteca.

\subsection{Relações com a comunidade}

5 Os jornais murais são “(...) diagramados e impressos em folhas únicas, exposto nos quadros arranjados em pontos de afluência de pessoas no interior das companhias (...)" (FORTES, 2003, p.264); é geralmente de caráter noticioso.

6 O mural é um “(...) veículo posto num suporte, o quadro mural, para a exibição de folhas isoladas ou dispostas em molduras em cores distintas, que delineiam as seções" (FORTES, 2003, p. 265). 
A COMUNICAÇÃO ORGANIZACIONAL COMO FERRAMENTA PARA A OTIMIZAÇÃO DO RELACIONAMENTO DE UMA BIBLIOTECA COM OS SEUS PÚBLICOS

Um bom relacionamento com a vizinhança não apenas é producente do ponto de vista das relações públicas - ao somar esforços para a obtenção de atitudes cooperativas e de boa vontade para com a iniciativa do espaço cultural -, como também do marketing. A comunidade pode vir a se tornar uma parceira dos esforços de ampliação dos visitantes e da base de usuários cadastrados. Ao se converterem em usuários ativos desde o primeiro momento, os integrantes da vizinhança se tornarão potenciais divulgadores - pelo boca a boca - da iniciativa da biblioteca junto a parentes, amigos e colegas de trabalho - mesmo aqueles de outros bairros -, os quais, a partir daí, podem ser incentivados a frequentar a biblioteca e a se tornarem novos usuários cadastrados.

Por este motivo, sugerimos que a comunidade seja um segmento prioritário no contexto dos esforços para a captação de usuários, especialmente na fase de implantação da biblioteca. O cadastramento de membros da vizinhança pode ser incentivado por meio do planejamento de visitas domiciliares de representantes da biblioteca - os quais podem ser terceirizados para cumprir esta função específica em um intervalo de tempo predeterminado -, munidos dos formulários necessários para se realizar o cadastramento ali mesmo, na porta da casa dos moradores. Além de uma breve apresentação oral a respeito da nova vizinha, a biblioteca, o enviado deve disponibilizar aos contatados um panfleto ou folder, com informações adicionais aos novos usuários, incluindo o endereço do website e os contatos do espaço cultural.

Do lado de dentro da biblioteca, por seu turno, o hall do espaço deverá abrigar exposições, preferencialmente de trabalhos de membros da comunidade. A biblioteca estará aberta às solicitações de artistas e artesãos para a organização conjunta das mostras. Além de agregar atrativos e movimentar a agenda cultural da instituição, a destinação do hall para exposições de trabalhos de membros da vizinhança configura-se como um programa de relações públicas com a comunidade. Aqui, o equipamento cedido, no caso, o espaço para as mostras, funciona como um veículo de comunicação dirigida aproximativa, na medida em que traz, para junto de uma organização, determinados públicos já identificados - especialmente os públicos vizinhos - possibilitando um contato direto entre ambos (FORTES, 2003, p. 327).

Ainda no bojo do relacionamento com a comunidade, as bibliotecas as quais possuam auditórios, podem cedê-los para eventos da comunidade, tais como cineclubes, reuniões etc. Com esta estratégia, pode-se atrair pessoas 
as quais, a princípio, não possuíam interesse nos serviços prestados pela organização - mormente o de empréstimo de livros. Atraídos para o interior da estrutura física do espaço cultural, ainda que por motivos outros que não os livros, os visitantes podem ser seduzidos a explorar o acervo. Neste ponto, entraria em ação um outro programa - o de comunicação organizacional no interior da própria biblioteca, destinado a tais visitantes esporádicos, os quais, de começo, não estavam a procura de uma biblioteca strictu sensu.

A organização que se dispor a ceder o seu auditório deve estabelecer

(...) parâmetros para regulamentar os empréstimos e controlar a sua demanda; podem ser criados formulários que descrevam em detalhes o que pode ser cedido, as prioridades, possibilidades e os trâmites dos pedidos. Não se prevê nenhuma forma de remuneração, e despesas fortuitas de manutenção serão cobertas pelo cedente (FORTES, 2003, p. 338).

O detalhamento das informações - relativas à cessão do hall e do auditório - pode ser divulgada em página específica do website da biblioteca.

A depender de sua arquitetura, até mesmo a fachada do edifício da biblioteca, ao tornar-se uma atração turística por si só, configura-se como um exemplo de cessão de equipamentos à comunidade por uma organização, já que o local - e, de resto, a vizinhança - passará a integrar o roteiro turístico de uma região.

\subsection{Recepção de sugestões}

Os usuários da biblioteca deverão ser convidados constantemente a opinar sobre o serviço prestado pela biblioteca e a sugerir títulos para o acervo. As sugestões de cada usuário devem ser valorizadas, embora, evidentemente estejam sujeitas ao orçamento disponível. Por meio do site institucional, ou off-line, na própria biblioteca, pode ser solicitado do usuário, o endereço de email. Assim, adquirido o livro, a biblioteca remeterá uma mensagem, avisando sobre a aquisição àquele que indicou o título, e reiterando a agradecimento pela sugestão.

As tradicionais caixas de sugestões continuam úteis, por permitirem a interação de usuários e colaboradores de forma discreta e anônima. Por meio destas, a biblioteca pode auscultar não somente sugestões, como ainda reclamações, queixas sobre o atendimento, elogios e dúvidas. Recomenda-se que a tampa da caixa seja lacrada de modo a evitar que a urna seja violada 
A COMUNICAÇÃO ORGANIZACIONAL COMO FERRAMENTA PARA A OTIMIZAÇÃO DO RELACIONAMENTO DE UMA BIBLIOTECA COM OS SEUS PÚBLICOS

e seu conteúdo subtraído. Os usuários e funcionários que se identificarem, disponibilizando alguma forma de contato, devem receber um retorno - ainda que por email.

\section{CONSIDERAÇÕES FINAIS}

É sintomático que as livrarias - maiormente as bookstores - recebam centenas de visitantes, muitos dos quais sem necessariamente ter o compromisso de comprar um livro, enquanto as bibliotecas abertas ao público não conseguem o mesmo sucesso. Em muitas bookstores, os visitantes estão a passeio, e entregam-se às títulos sem a mesma objetividade com a qual costumam acorrer aqueles que frequentam o acervo das bibliotecas. Em livrarias, é comum ver pessoas sentadas, lendo ou apenas folheando um livro. Atividades que poderiam ser realizadas em uma biblioteca.

Estratégias de comunicação organizacional podem contribuir para reabilitar as bibliotecas ao papel de centros de lazer cultural, para além de um local de estudo ou de fonte de pesquisa colegial. A reversão do quadro passa por um reposicionamento dos espaços culturais como áreas para a prática do lazer cultural, para a consulta descompromissada ao acervo, para o passeio mais demorado, e não apenas para a pesquisa objetiva, ou para a retirada de um título pré-selecionado. $\mathrm{E}$, nesse sentido, estratégias e instrumentos de comunicação organizacional podem contribuir para que as bibliotecas sejam atualizadas e ressignificadas, sem necessariamente comprometer de modo expressivo o orçamento geralmente exíguo de tais espaços culturais.

O instrumental da comunicação organizacional, o qual pode ser elencado e sugerido em um plano de comunicação, abrange uma diversa gama de ferramentas, como house organs, produção de audiovisuais, organização de visitas guiadas etc.

Está entre os objetivos dos esforços sugeridos aqui, a ampliação: do número de visitantes, da base de usuários efetivamente cadastrados e do volume de livros emprestados. Ante aos que já figuravam como usuários da biblioteca, o que se almeja é o aumento da frequência das visitas e a ampliação do volume de leitura por meio da solicitação de empréstimos de livros.

A comunicação organizacional tem a faculdade de contribuir com a ampliação e estreitamento do relacionamento da instituição cultural com os seus diversos públicos, corroborando com o aumento do número de usuários cadastrados na biblioteca, bem como o aumento da frequência das 
visitas destes. E as contribuições potenciais não se restringem a parte meio, pois se estendem a parte fim, já que a comunicação tem o potencial de amplificar a mensagem de cultura e cidadania de uma biblioteca.

\section{REFERÊNCIAS}

ANDRADE, Cândido Teobaldo de Souza. Curso de Relações Públicas: relações com os diferentes públicos. $6^{\text {a }}$ Ed. São Paulo: Pioneira Thomson Learning, 2003. 308 p.

BORGES, Priscilla. Mais de mil municípios estão sem biblioteca pública. Último Segundo, 30 abr. 2010. Disponível em: http://ultimosegundo.ig.com.br/educacao/mais-de-mil-municipios-estao-sem-biblioteca-publica/n1237601002057.html. Acesso em 06/04/2015.

CIEGLINSKI, Amanda. Ver TV é atividade preferida pelo brasileiro no tempo livre, leitura fica em sétimo. Agência Brasil, Brasília, 28 mar. 2012. Disponível em: http://memoria.ebc. com.br/agenciabrasil/noticia/2012-03-28/ver-tv-e-atividade-preferida-pelo-brasileiro-no-tempo-livre-leitura-fica-em-setimo. Acesso em 07/04/2015.

DAYCHOUW, Merhi. 40 ferramentas e técnicas de gerenciamento. Rio de Janeiro: Brasport, 2007. $245 \mathrm{p}$.

MILANESI, Luís. Biblioteca. Cotia-SP: Ateliê Editorial, 2002. 116 p.

FORTES, Waldyr Gutierrez. Relações públicas - processo, funções, tecnologia e estratégias. $2^{a}$ Ed. São Paulo: Summus, 2003. 394 p.

KUNSCH, Margarida Maria Krohling. Planejamento de Relações Públicas na comunicação integrada. $2^{a}$ Ed. São Paulo: Summus, 2002. (Col. Novas buscas em Comunicação; vol. 17).

MARCONI, Joe. Relações públicas - o guia completo. Trad. Anna Maria Dalle Luche. São Paulo: Cengage Learning, 2009. 211 p.

REGO, Francisco Gaudêncio Torquato do. Jornalismo empresarial: teoria e prática. $4^{\mathrm{a}}$ Ed. São Paulo: Summus, 1984 (Col. Novas Buscas em Comunicação). 191 p.

RECEBIDO EM: 03/06/2015

ACEITO PARA PUBLICAÇÃO: 01/08/2015

\section{Tiago Eloy Zaidan}

Mestre em Comunicação Social pela Universidade Federal de Pernambuco e professor do Instituto Federal de Educação, Ciência e Tecnologia da Paraíba. Integrou o projeto de popularização e difusão da ciência e tecnologia da Coordenadoria de Ensino de Ciências do Nordeste da Universidade Federal de Pernambuco (CECINE / UFPE / Ministério da Ciência e Tecnologia), como produtor e apresentador do programa de rádio "Ondas das Ciência". 
